\title{
Pengaruh Media Sosial Terhadap Akhlakul Karimah Remaja Desa Air Gegas
}

\author{
Ridoni; Dian Puspita Eka Putri; Gita Wulandari; Novita Sari; \\ Rizky Tamila
}

\author{
Fakultas Tarbiyah, \\ IAIN Syaikh Abdurrahman Siddik Bangka Belitung \\ Bangka, Indonesia
}

\begin{abstract}
ridoni20121997@gmail.com; dianpuspitaekap@gmail.com; gitawl123@gmail.com; novitasr12@gmail.com; rizkytml3@gmail.com;
\end{abstract}

\begin{abstract}
Adolescence is a period that shows the nature of the transition from childhood to adolescence. Social media has a huge impact on the morals of teenagers today. Simple examples are not uncommon for teenagers' daily activities to be shared via social media. As is evident in Air Gegas Village, they are accustomed to being educated and nurtured by their parents to do, namely good deeds (behavior), but on the other hand, there are still some teenagers who have bad morals. So that it can result in them being influenced by the social media they use in everyday life without any direct filter from parents. Because the impact of that action can affect the morals of a teenager. This research uses quantitative methods. This research will also measure the level of use of social media. Akhlakul karimah in Air Gegas village increased by a value of 956. This shows that the existing Social Media variables contribute positively to morals, so that the more complete social media is, the more akhlakul karimah teenagers in Air Gegas Village will increase. There is an influence of social media on the morals of teenagers in Air Gegas Village.
\end{abstract}

Remaja merupakan masa yang menunjukkan sifat transisi dari kanak-kanak menjadi remaja. Media sosial membawa dampak sangat besar terhadap akhlakul karimah remaja di masa sekarang. Contoh sederhana tidak jarang aktivitas sehari-hari remaja di bagikan lewat media sosial. Seperti yang nyata terjadi di Desa Air Gegas, mereka terbiasa dididik dan diasuh oleh kedua orang tuanya untuk melakukan, yakni perbuatan (perilaku) yang baik, namun disisi yang lain, masih terdapat beberapa remaja yang memiliki akhlak yang kurang baik. Sehingga dapat mengakibatkan mereka terpengaruh oleh media sosial yang digunakannya dalam kehidupan sehari-hari tanpa ada filter dari orang tua secara langsung. Dampak yang ditimbulkan dari perbuatan itu dapat mempengaruhi akhlakul karimah seorang remaja. Penelitian ini menggunakan metode Kuantitatif.Penelitian ini dilakukan akan diukur pula tingkat penggunaan media social. akhlakul karimah desa Air Gegas meningkat sebesar nilai 956. Hal tersebut menunjukkan bahwa variabel Media Sosial yang 
ada berkontribusi positif bagi akhlakul karimah, sehingga makin komplet Media Sosial, makin meningkat pula akhlakul karimah remaja Desa Air Gegas.Ada pengaruh media sosial terhadap akhlakul karimah remaja desa Air Gegas.

Keywords: Social Media, The formation Of Akhlakul Karimah, Teenager.

\section{A. Pendahuluan}

Desa Air Gegas merupakan salah satu kecamatan di Bangka Selatan, yang memiliki 10 desa di antaranya (Air Gegas, Bencah , Pergam, Tepus, Delas, Nyelanding, Sidoharjo, Nangka, Ranggas, Air Bara), ${ }^{1}$ dengan jumlah penduduk kurang lebih 2500 Kepala Keluarga, dengan jumlah remaja yang cukup banyak yakni 100 remaja. Berikut kegiatan remaja desa Air gegas.

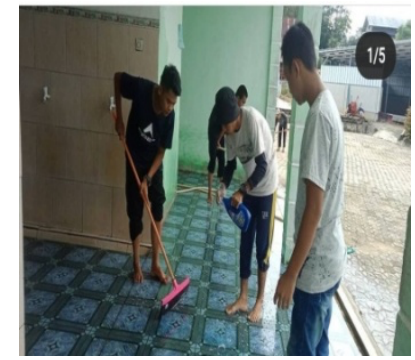

Kerja Bakti

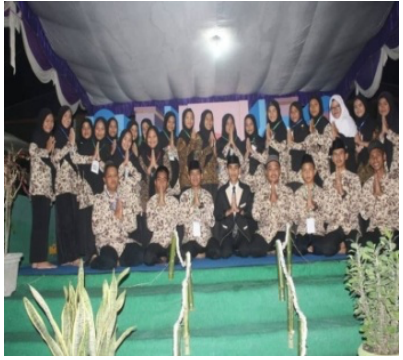

Perayaan Maulid

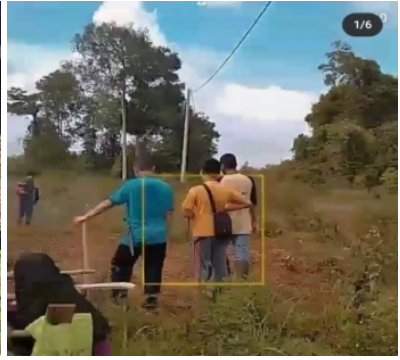

Membersihkan Ladang

Kondisi seperti ini mencerminkan bahwa remaja yang melakukan kegiatan sudah didukung oleh Sumber Daya Manusia (SDM) yang cukup dan memadai. Meskipun dengan begitu masih ada remaja yang melanggar norma-norma agama.

Dengan merambahnya dunia IPTEK yang semakin hari semakin tidak bisa diperkirakan, ada akibat yang ditimbulkan dari kalangan remaja, dimana setiap kegiatan para remaja selalu membawa handphone, kondisi seperti inilah yang tidak bisa dikendalikan oleh siapa pun kecuali remaja itu sendiri. Mempertimbangkan kembali terdapat dalam handphone para remaja, yakni media sosial yang mereka unduh dari playstore, app market dan lain sebagainya. Sementara itu orang tua dari

${ }^{1}$ Samsul, (Ketua Umum KPU Kec. Air Gegas), wawancara oleh Novita Sari, Desa Air Gegas. 
para remaja mengajarkan bahwa ada batasan dalam menggunakan media sosial, selain untuk mengetahui berita, belajar dan sebagainya.

Media sosial membawa semua orang agar tertarik dan ikut serta memberikan feedback secara terbuka, berbagi informasi tanpa ada batasan waktu, memberi komentar. ${ }^{2}$ Dengan media sosial, seseorang secara tidak langsung memiliki pengaruh yang besar dalam kehidupan. Seseorang yang awalnya sederhana bisa menjadi luar biasa hebat dengan media sosial dan bisa saja sebaliknya. Kalangan masyarakat khususnya remaja, media sosial sudah menjadi candu yang membuat pengaksesnya tiada hari tanpa membuka media sosial. ${ }^{3}$

Remaja yang memiliki media sosial biasanya memiliki aktivitas seperti memposting tentang aktivitas pribadinya, foto bersama teman sebaya, kuliner, curhat, serta mention tag. ${ }^{4}$ Dengan media sosial orang bebas memberikan komentar dan berpendapat tanpa ada rasa khawatir sedikit pun. Karena dalam media sosial ada akun sebagai awal masuknya, dengan akun sangat mudah memalsukan jati diri sehingga dapat melakukan kejahatan. Namun dalam perkembangannya selama pendidikan di sekolah, remaja diajarkan untuk mencari jati diri yang sebenarnya dengan melihat lingkungan sekitar. Saat ini yang terjadi pada remaja adalah menganggap bahwa dirinya semakin aktif di media sosial semakin dianggap merekalah yang gaul. Sedangkan remaja yang tidak memiliki media sosial dianggap awam atau tidak mengikuti trend". 5

Remaja yang biasa kita temukan dalam kehidupan sehari-hari yang menggunakan media sosial akan menjadi hiperaktif karena sering membagikan aktivitas sehari-hari secara tidak langsung menggambarkan lifestyle. Kalangan

${ }^{2}$ Resti Sri Elwani and Firman Kurniawan, 'Pemanfaatan Media Sosial Dalam Pemasaran Sosial Bagi Remaja', Jurnal Komunikasi, 12.1 (2020), 64-80.

${ }^{3}$ Wahyu Rahardjo and others, 'Adiksi Media Sosial Pada Remaja Pengguna Instagram Dan WhatsApp: Memahami Peran Need Fulfillment Dan Social Media Engagement', Jurnal Psikologi Sosial, 18.1 (2020), 5-16.

${ }^{4}$ Anang Sugeng Cahyono, 'Pengaruh Media Sosial Terhadap Perubahan Sosial Masyarakat Di Indonesia', Jurnal Publiciana, 9.1 (2016), 140-57.

${ }^{5}$ Budiarti S Meilanny Putri Wilga Secsio Ratsja, Nunung R Nurwanti, 'Pengaruh Media Sosial Terhadap Perilaku Remaja', Prosiding Penelitian Dan Pengabdian Kepada Masyarakat, 3.1 (2016), hlm. 48. <https://doi.org/10.24198/jppm.v3i1.13625>. 
remaja yang menjadi hiperaktif di media sosial ini juga sering memposting kegiatan sehari-hari mengikuti trend. ${ }^{6}$ Padahal apa yang mereka bagikan tidak selalu menggambarkan kehidupan yang sebenarnya. Remaja yang membagikan sisi kehidupan yang penuh kesenangan di media sosial, tidak dipungkiri kenyataannya terkadang mereka merasa kesepian. Manusia sebagai aktor yang kreatif mampu menciptakan berbagai hal, salah satunya adalah ruang interaksi dunia maya. Setiap individu mampu menampilkan karakter diri yang berbeda ketika berada di dunia maya dengan dunia nyata. ${ }^{7}$

Kaidah akhlak dalam agama Islam menggambarkan kenyataan hidup manusia, manusia yang dinyatakan sebagai makhluk yang memiliki kelebihan dibandingkan dengan makhluk-makhluk lainnya, justru manusia memiliki kelemahan dan kebiasaan manusia seperti kebutuhan material dan spiritual. Kelemahan-kelemahan yang dimiliki manusia sehingga memungkinkan mereka melakukan pelanggaran dan kesalahan. ${ }^{8}$

Seperti yang nyata terjadi di Desa Air Gegas, mereka terbiasa dididik dan diasuh oleh kedua orang tuanya untuk melakukan akhlakul karimah, yakni perbuatan (perilaku) yang baik, namun disisi yang lain, masih terdapat beberapa remaja yang memiliki akhlak yang kurang baik. Sehingga dapat mengakibatkan mereka terpengaruh oleh media sosial yang digunakannya dalam kehidupan sehari-hari tanpa ada filter dari orang tua secara langsung. Karena dampak yang ditimbulkan dari perbuatan itu dapat mempengaruhi akhlakul karimah seorang remaja. ${ }^{9}$

Dengan adanya kemudahan dan segala fitur yang disuguhkan media social tak jarang seseorang dapat terpengaruh. Maka dari itu penulis ingin mengetahui "Pengaruh Media Sosial Terhadap Akhlakul Karimah Remaja Desa Air Gegas". Penelitian ini menggunakan metode Kuantitatif. Cross sectional adalah Penelitian

\footnotetext{
${ }^{6}$ Putri Wilga Secsio Ratsja, Nunung R Nurwanti.

${ }^{7}$ Rizki Aprilia, Aat Sriati, and Sri Hendrawati, 'Tingkat Kecanduan Media Sosial Pada Remaja', Journal of Nursing Care, 3.1 (2020).

${ }^{8}$ Siti Nor Hayati, 'KARIMAH SISWA ( Studi Kasus Pada Siswa Kelas XI MAN Purwoasri', 2015, hlm.14.

${ }^{9}$ Hasil wawancara dengan Ibu Dona Milisa selaku orang tua remaja desa Air Gegas.
} 
yang dilakukan dengan teknik mengumpulkan data hanya sekali (yang dilakukan selama periode hari, minggu atau bulan). Untuk menjawab pertanyaan. Metode Penelitian Cross sectional metode yang mempelajari objek dalam kurun waktu tertentu.

Penelitian ini akan diukur tingkat penggunaan media social. Tingkat penggunaan media sosial dapat dilihat dari beberapa kali penggunaannya pengambilan satuan ukuran minggu untuk penggunaan media sosial menjadikan responden dengan mudah menentukan tingkat penggunaannya.

- Populasi yakni mengambil data dari pihak Desa Air Gegas, observasi ini menggunakan metode Multistage Random Sampling (teknik penarikan acak bertingkat) berbasis Cluster, dengan menggunakan sampel sebanyak 20 responden (Remaja).

- Sampel diambil berdasarkan kategori remaja baik laki-laki maupun perempuan. Pengolaan data statistic dilakukan dengan cara komputerisasi.

- Hasil penyebaran angket meliputi pemaparan tentang:

a. Intensitas penggunaan media sosial.

b. Akhakul karimah remaja.

Pengisian kuisioner menggunakan Kuantitatif Metode ini memudahkan peneliti untuk mengetahui pengaruh dalam sebuah populasi menggunakan sample. Sample yang dipilih disesuikan dengan metode yang tepat agar menggambarkan kondisi populasi sesungguhnya, dan dapat menghemat biaya penelitian secara efektif. Sejatinya, sample yang digunakan benar-benar mewakili dan menggambarkan karakteristik populasi yang ada. Karena data yang didapat dari sample dapat digunakan dalam menaksirkan populasi. Sample represantatif digunakan untuk mewakili populasi. Sample representative mempunyai ciri karakteristik relatif sama atau yang sama dengan ciri karakteristik populasi yang ada. Tingkat representatif sample yang digunakan dari populasi tertentu sanat tergantung 
pada jenis sample yang digunakan, cara pengambilan, ukuran sample yang digunakan. ${ }^{10}$

\section{B. Pembahasan}

\section{Media Sosial}

Media sosial merupakan sebuah media online, dimana setipa penggunanya bisa dengan mudah berbagi, berpatisipasi, membuat blog, jejaring sosial dam wiki, grup dalam dunia vitrual. Jejaring sosial merupakan situs, dimana setiap orang dapat membuat web page pribadi, kemudian terhubung dengan teman-teman untuk berbagi informasi dan berkomunikasi. Jejaring sosial yang besar antara lain Facebook, Instragram, WhatsApp, Twitter. Disamping itu media sosial juga mengajak siapa saja untuk tertarik menggunakannya agar berpatisipasi dengan memberikan feedback, komentar, serta membagi informasi dalam waktu cepat dan tak terbatas. ${ }^{11}$

Macam-macam media sosial yang digunakan orang pada saat ini. Setiap media sosial memiliki kelebihannya masing-masing. Berikut klasifikasi macammacam jejaring sosial berdasarkan fungsinya dan kegunaannya: a) Konten Kolaborasi (contohnya Wikipedia); b) Blog dan microblog (contohnya Twitter); c) Situs jejaring sosial berita (contohnya Digg); d) Konten video (contohnya Youtube).

Beberapa dampak positif dan negatif dari media sosial: ${ }^{12}$

\begin{tabular}{ll}
\hline \multicolumn{1}{c}{ Dampak Posotif } & \multicolumn{1}{c}{ Dampak Negatif } \\
\hline Tempat promosi yang baik dan murah. & Menggangu kegiatan belajar remaja. \\
Memperluas jaringan pertemanan. & Bahaya kejahatan. \\
Media komunikasi yang mudah. & Bahaya penipuan. \\
Tempat mencari informasi yang & Tidak semua pengguna media sosial \\
bermanfaat. & sopan. $^{13}$ \\
\hline
\end{tabular}

${ }^{10}$ Wahyu Supriyanto and others, 'Kecenderungan Sivitas Akademika Dalam Memilih Sumber Referensi Untuk Penyusunan Karya Tulis Ilmiah Di Perguruan Tinggi 1', 13.1 (2017), 79-86.

${ }^{11}$ Elwani and Kurniawan.

${ }^{12}$ Yoyon M Darusman and others, 'Pentingnya Pemahaman Tentang Kemanfaatan Dan Kemudaratan Media Sosial', Abdi Laksana: Jurnal Pengabdian Kepada Masyarakat, 2.1 (2021), 173-79.

${ }^{13}$ Putri Wilga Secsio Ratsja, Nunung R Nurwanti. 'Pengaruh Media Sosial Terhadap Perilaku Remaja, 2016, hlm 48. 
|DIAN dkk | Pengaruh Media Sosial Terhadap...

\section{Akhlakul Karimah}

"Akhlak baik yakni semua tingkah laku yang terpuji (Mahmudah) atau Kelebihan (Fadhilah). Tingkah laku batin merupakan awal terbentuknya tingkah laku, yakni berupa kelakuan batin dan sifat yang juga berbolak balik yang dapat menimbulkan berbolak balik perbuatan jasmani manusia.

Akhlakul karimah yakni tingkah laku yang menandakan bahwa adanya kesempurnaan Iman seseorang terhadap Rabb-Nya. Hamzah Ya'qub mengatakan akhlak yang baik merupkan mata rantai Iman yang kokoh. Misalnya, malu berbuat jahat terhadap orang tua adalah contoh sederhana akhlak yang baik. Al-Ghozli menerangkan keutaman akhlakul karimah yang dimiliki seseorang seperti benar, sabar, tawakal, ini dinyatakan sebagai gerak jiwa dan gambaran batin yang secara tidak langsung menjadi akhlaknya". ${ }^{14}$

Seseorang yang berakhlakul karimah dalam kehidupan seharinya ada manfaat yang diperolah, tertera pada Al-Qur'an dan Al-Hadist. Allah berfirman :"Barangsiapa yang mengerjakan amal saleh, baik laki-laki maupun perempuan dalam keadaan beriman, maka sesungguhnya akan Kami beri balasan kepada mereka dengan pahala yang lebih dari apa yang telah merek kerjakan”. (QS. AnNahl: 97). ${ }^{15}$

\section{Remaja}

Remaja berasal dari kata latin adolensence yang memiliki arti tumbuh atau tumbuh menjadi dewasa. Istilah adolensence ini mempunyai makna yang sangat luas yang mencakup kematangan mental, emosional, fisik, emosional, dan sosial. ${ }^{16}$ Tahap perkembangan remaja dibagi menjadi empat bagian menurut Hadianto yang dikutip oleh Wilga dkk, yakni masa pra-remaja 10-12 tahun, masa remaja awal

\footnotetext{
${ }^{14}$ Hayati dan Siti Nor, 'Karimah Siswa (Studi Kasus Pada Siswa Kelas XI MAN Purwoasri, 2015, hlm. 14.

${ }^{15} \mathrm{Al}-$ Qur'an dan Terjemahannya, (Jakarta: Pustaka Jaya Ilmu), hlm. 278.

${ }^{16}$ Putri Wilga Secsio Ratsja, Nunung R Nurwanti.
} 
12-15 tahun, masa remaja pertengahan 15-18 tahun, dan masa remaja akhir 18-21 tahun. ${ }^{17}$

Masa remaja merupakan masa peralihan dari masa kanak-kanak menjadi dewasa yang mengalami perkembangan dari berbagai aspek dengan ditandai pertumbuhan fisik, perkembangan seksual, cara berpikir, emosi yang meluap-luap, mulai tertarik dengan lawan jenis, dan menarik perhatian lingkungan serta terkait dengan kelompok. ${ }^{18}$

\section{Pengaruh Media Sosial Terhadap Akhlakul Karimah Remaja Desa Air Gegas}

Tabel 3.11 Hasil Uji Koefisien

Coefficients $^{\mathrm{a}}$

\begin{tabular}{|c|c|c|c|c|c|}
\hline \multirow[b]{2}{*}{ Model } & \multicolumn{2}{|c|}{$\begin{array}{c}\text { Unstandardized } \\
\text { Coefficients }\end{array}$} & \multirow{2}{*}{$\begin{array}{c}\text { Standardized } \\
\text { Coefficients } \\
\text { Beta }\end{array}$} & \multirow[b]{2}{*}{$\mathrm{t}$} & \multirow[b]{2}{*}{ Sig. } \\
\hline & B & $\begin{array}{l}\text { Std. } \\
\text { Error }\end{array}$ & & & \\
\hline $\begin{array}{l}\text { Constan } \\
\text { t) }\end{array}$ & .725 & 2.220 & & .327 & .748 \\
\hline $\begin{array}{l}\text { Media } \\
\text { Sosial } \\
\text { (X1) }\end{array}$ & .956 & .226 & .706 & 4.233 & .001 \\
\hline
\end{tabular}

a. Dependent Variable: Akhlakul Karimah Remaja (Y)

Berdasarkan analisis data dengan menggunakan SPSS 16.0, maka diperoleh hasil persamaan regresi sebagai berikut: $Y=725-956+e$

Persamaan regresi di atas memperlihatkan hubungan antara variabel independen dengan variabel dependen secara parsial, dari persamaan tersebut dapat diambil kesimpulan bahwa:

17 Aprilia, Sriati, and Hendrawati.

${ }^{18}$ Reni Ferlitasari and Ellya Rosana, 'Pengaruh Media Sosial Instagram Terhadap Perilaku Keagamaan Remaja', Sosio Religia, 1.2 (2020). 
|DIAN dkk | Pengaruh Media Sosial Terhadap...

1. Nilai constanta adalah 725 , artinya jika tidak terjadi perubahan variable Media Sosial (nilai X1=0) maka akhlakul karimah remaja Desa Air Gegas ada sebesar 725 satuan.

2. Nilai koefisien regresi Media Sosial adalah 956, artinya jika variabel Media Sosial (X1) meningkat sebesar 1\% dan konstanta (a) adalah 0 (nol), maka akhlakul karimah desa Air Gegas meningkat sebesar nilai 956. Hal tersebut menunjukkan bahwa variabel Media Sosial yang ada berkontribusi positif bagi akhlakul karimah, sehingga makin komplet Media Sosial, makin meningkat pula akhlakul karimah remaja Desa Air Gegas.

Tabel 3.12 Hasil Uji t (parsial)

Coefficients $^{\mathrm{a}}$

\begin{tabular}{|c|c|c|c|c|c|c|}
\hline & \multirow[b]{2}{*}{ Model } & \multicolumn{2}{|c|}{$\begin{array}{c}\text { Unstandardized } \\
\text { Coefficients }\end{array}$} & \multirow{2}{*}{$\begin{array}{c}\text { Standardized } \\
\text { Coefficients }\end{array}$} & \multirow[b]{2}{*}{$\mathrm{t}$} & \multirow[b]{2}{*}{ Sig. } \\
\hline & & B & Std. Error & & & \\
\hline & (Constant) & .725 & 2.220 & & .327 & .748 \\
\hline & $\begin{array}{c}\text { Media } \\
\text { Sosial (X1) }\end{array}$ & .956 & .226 & .706 & 4.233 & .001 \\
\hline
\end{tabular}

a. Dependent Variable: Akhlakul Karimah Remaja (Y)

Berdasarkan tabel 3.12 dengan mengamati baris, kolom $\mathrm{t}$ dan sig. Bisa dijelaskan sebagai berikut:

1. Pengaruh variabel media sosial terhadap akhlakul karimah remaja $\left(\mathrm{H}_{1}\right)$

2. Variabel media sosial $\left(\mathrm{X}_{1}\right)$ berpengaruh secara positif dan signifikan terhadap akhlakul karimah remaja Desa Air Gegas. Hal ini terlihat dari signifikan media sosial $\left(\mathrm{X}_{1}\right) 0,01<0,05$, dan nilai $\mathrm{t}_{\text {tabel }}=\mathrm{t}(\alpha / 2 ; \mathrm{n}-1)=\mathrm{t}(0,025 ; 19)=2.09302$. Berarti nilai $t_{\text {hitung }}$ lebih besar dari $t_{\text {tabel }}(4.233>2.09302)$, maka Ho ditolak dan $\mathrm{H}_{1}$ diterima. Sehingga hipotesis yang berbunyi terdapat pengaruh media sosial terhadap akhlakul karimah remaja Desa Air Gegas secara parsial diterima.

\section{Hasil Uji Koefisien Determinasi}

Koefisien determinasi $\left(\mathrm{R}^{2}\right)$ pada intinya mengukur seberapa jauh kemampuan model dalam menerangkan variasi variabel dependen. Nilai koefisien 
determinasi adalah nol dan satu nilai $\mathrm{R}^{2}$ kemampuan variabel-variabel independen dalam menjelaskan variasi variabel dependen amat terbatas, nilai yang mendekati satu berarti variabel-variabel independen memberikan hampir semau informasi yang dibutuhkan untuk memprediksi variasi variabel-variabel dependen, berdasarkan uji $\mathrm{R}^{2}$ yang dapat dilihat pada tabel 3.13.

\section{Tabel 3.13 Hasil Uji Koefisien Determinasi} Model Summary

\begin{tabular}{|l|c|r|r|r|}
\hline Model & R & $\begin{array}{c}\text { R } \\
\text { Square }\end{array}$ & $\begin{array}{c}\text { Adjusted } \\
\text { R Square }\end{array}$ & Std. Error of the Estimate \\
\hline 1 & $.706^{\mathrm{a}}$ & .499 & .471 & 1.60041 \\
\hline
\end{tabular}

a. Predictors: (Constant), Media Sosial (X1)

Berdasarkan tabel 3.13 dapat diketahui bahwa nilai koefisien determinasi terdapat pada nilai Adjusted $R$ Square sebesar 0.471. Hal ini berarti kemampuan variabel bebas dalam menjelaskan variabel terikat sebesar $47,1 \%$ sisanya $53 \%$ dijelaskan oleh variabel lain yang tidak dibahas dalam penelitian ini.

Ada pengaruh media sosial terhadap akhlakul karimah remaja desa Air Gegas.

\section{Kesimpulan}

Pengaruh media sosial terhadap akhlakul karimah remaja di Desa Air Gegas berkontribusi sangat positif. Karena dapat dilihat dari hasil survey yang telah dilakukan. Sehingga makin komplet Media Sosial yang digunakan maka semakin meningkat pula akhlakul karimah remaja Desa Air Gegas.

\section{Daftar Pustaka}

Al-Qur'an dan Terjemahannya, (Jakarta: Pustaka Jaya Ilmu), hlm. 278.

Aprilia, Rizki, Aat Sriati, and Sri Hendrawati, 'Tingkat Kecanduan Media Sosial Pada Remaja', Journal of Nursing Care, 3.1 (2020)

Cahyono, Anang Sugeng, 'Pengaruh Media Sosial Terhadap Perubahan Sosial Masyarakat Di Indonesia', Jurnal Publiciana, 9.1 (2016), 140-57

Darusman, Yoyon M, Bastianon Bastianon, Susanto Susanto, Dyas Mulyani Benazir, and Tato Setiawan, 'Pentingnya Pemahaman Tentang Kemanfaatan Dan Kemudaratan Media Sosial', Abdi Laksana: Jurnal Pengabdian 
Kepada Masyarakat, 2.1 (2021), 173-79

Elwani, Resti Sri, and Firman Kurniawan, 'Pemanfaatan Media Sosial Dalam Pemasaran Sosial Bagi Remaja', Jurnal Komunikasi, 12.1 (2020), 64-80

Ferlitasari, Reni, and Ellya Rosana, 'Pengaruh Media Sosial Instagram Terhadap Perilaku Keagamaan Remaja', Sosio Religia, 1.2 (2020)

Hayati, Siti Nor, 'KARIMAH SISWA ( Studi Kasus Pada Siswa Kelas XI MAN Purwoasri', 2015, hlm.14

Putri Wilga Secsio Ratsja, Nunung R Nurwanti, Budiarti S Meilanny, 'Pengaruh Media Sosial Terhadap Perilaku Remaja', Prosiding Penelitian Dan Pengabdian Kepada Masyarakat, $3.1 \quad$ (2016), hlm. 48. $<$ https://doi.org/10.24198/jppm.v3i1.13625>

Rahardjo, Wahyu, Nurul Qomariyah, Inge Andriani, Matrissya Hermita, and Firda Nur Zanah, 'Adiksi Media Sosial Pada Remaja Pengguna Instagram Dan WhatsApp: Memahami Peran Need Fulfillment Dan Social Media Engagement', Jurnal Psikologi Sosial, 18.1 (2020), 5-16

Supriyanto, Wahyu, Rini Iswandiri, Pustakawan Universitas, Gadjah Mada, Klaster Saintek, and Klaster Sosio, 'Kecenderungan Sivitas Akademika Dalam Memilih Sumber Referensi Untuk Penyusunan Karya Tulis Ilmiah Di Perguruan Tinggi 1', 13.1 (2017), 79-86

Samsul, (Ketua Umum KPU Kec. Air Gegas), wawancara oleh Novita Sari, Desa Air Gegas. 